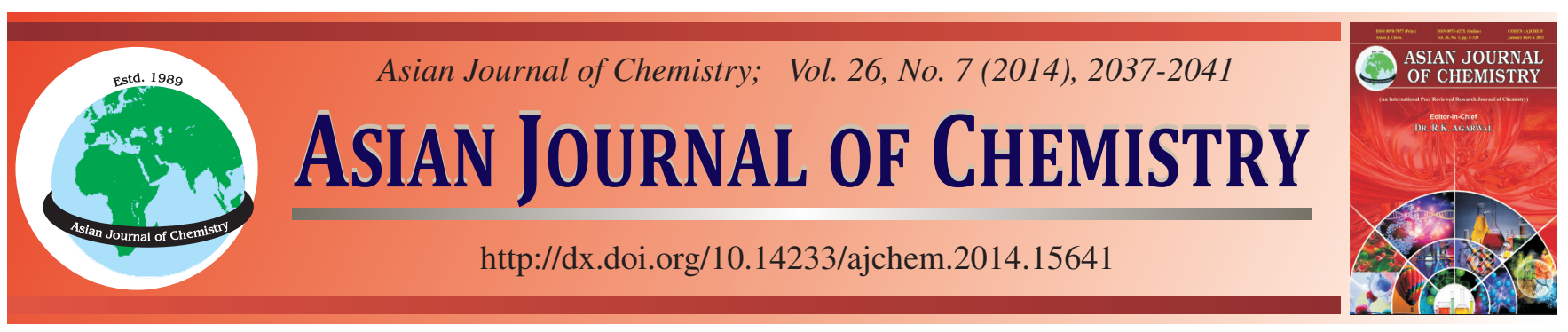

\title{
Study on Resonance Rayleigh Scattering Spectra, Non-linear Scattering Spectra of Alizarin Red-Cetylpyridinium Bromide-Lead System and its Analytical Application
}

\author{
JiA-Hong He, Qiang Xu, Zhi-Gang XIE and Zhong-Rong Song*
}

School of Materials and Chemical Engineering, Chongqing University of Arts and Sciences, Yongchuan 402160, P.R. China

*Corresponding author: E-mail: 20110901036@cqu.edu.cn

\begin{abstract}
In $\mathrm{pH}$ 7.6 $\mathrm{NH}_{3} \cdot \mathrm{H}_{2} \mathrm{O}$ medium, Alizarin red and cetylpyridinium bromide could react with lead to form ternary ion-association complex. As a result, the intensities of resonance Rayleigh scattering and the resonance non-linear scattering such as second-order scattering and frequency-doubling scattering were enhanced greatly. The maximum wavelength of resonance Rayleigh scattering, second-order scattering and frequency-doubling scattering was located at 288, 544 and $390 \mathrm{~nm}$, respectively. The enhancement of the three scattering intensity $(\Delta \mathrm{I})$ was directly proportional to the concentration of lead in the range of $0.12-3.78 \mu \mathrm{g} / \mathrm{mL}$ for resonance Rayleigh scattering, $0.09-2.86$ $\mu \mathrm{g} / \mathrm{mL}$ for second-order scattering and $0.07-2.86 \mu \mathrm{g} / \mathrm{mL}$ for frequency-doubling scattering] and the detection limits $(3 \sigma)$ were $2.1 \mathrm{ng} / \mathrm{mL}$ for resonance Rayleigh scattering method, $7.4 \mathrm{ng} / \mathrm{mL}$ for second-order scattering and $8.6 \mathrm{ng} / \mathrm{mL}$ for frequency-doubling scattering], respectively. Therefore, a new, high-sensitive method of resonance Rayleigh scattering and resonance non-linear scattering was developed to determine trace amount of lead. In this work, the characteristic of resonance Rayleigh scattering, second-order scattering and frequencydoubling scattering] spectra of the Alizarin red-cetylpyridinium bromide- $\mathrm{Pb}$ (II) system has been studied. Meanwhile, the influence of $\mathrm{pH}$, resonance probe dosage, coexisting substances and other factors were investigated. The results show that the method exhibits a good selectivity, high sensitivity and easy operation. In addition, the mechanism of the enhancement of scattering spectra was discussed.
\end{abstract}

Keywords: Resonance Rayleigh scattering, Frequency doubling scattering, Alizarin red, Lead, Cetylpyridinium bromide.

ᄂ - - - - - - - - - - - - - - - - - - - - - - - - - -

\section{INTRODUCTION}

Lead is one of the most common pollutants in the environment, toxic to the human beings and animals without any known physiological function, which accumulates in the organism. High level of lead in the body of children causes damage to the brain, nervous system, behavior, learning and hyperactivity. Adults exposed to lead may cause disorders, memory and concentration problems, muscle and joint pain ${ }^{1}$. Therefore, the determination of lead in all sources even at ultratrace level especially in foods, confectionery, drinks, etc. is important and considerable in analytical interest. Up to now, the most common analytical methods for determination of lead at trace level are spectrophotometry ${ }^{2}$, anodic stripping voltammetry ${ }^{3,4}$, atomic absorption method ${ }^{5-7}$, atomic fluorescence spectrometry ${ }^{8,9}$, etc. Although these methods have some advantages for the determination of lead, most of them require timeconsuming procedures, derivatization steps, or expensive instruments. So, it is necessary to develop a simple, sensitive and convenient method for the detection of lead.

Resonance Rayleigh scattering (RRS) method and resonance non-linear scattering method (RNLS), which include second-order scattering (SOS) and frequency doubling scattering (FDS), are new analytical techniques developed in $1990 \mathrm{~s}^{10}$. It has been widely applied to the quantitative analysis of pharmaceuticals ${ }^{11}$, proteins ${ }^{12}$, nucleic acid $^{13}$, metal ions ${ }^{14}$, surfactant ${ }^{15}$ because of the high sensitivity and simplicity. The above researches laid the foundation for the determination of metal ions like lead.

Our experiment results discovered that in alkaline medium, resonance Rayleigh scattering, second-order scattering (SOS) and frequency doubling scattering (FDS) intensities of lead, Alizarin red (AR), cetylpyridinium bromide (CPB) and the binary ligand complexes among lead, AR, CPB were weak. When the lead reacted with the binary ligand complex of ARCPB to form ternary ion-association, their scattering intensities were boosted greatly. The intensities of the three scattering were directly proportional to the concentration of lead in a certain range. The three methods all could be applied to determine Ami, but the sensitivity of RRS was higher than those of SOS and FDS. So the optimum reaction conditions, the influences of coexis-ting substances and the properties of analytical chemistry were investigated by RRS. 


\section{EXPERIMENTAL}

A Hitachi F-7000 fluorescence spectrophotometer (Tokyo, Japan) was used to record the RRS and measure the scattering intensity; A UV-8500 spectrophotometer (Tianmei Corporation, Shanghai, China) was used to record the absorption spectra; An S-2F digital pH meter (Leici, Shanghai, China) was used to adjust $\mathrm{pH}$.

The standard solution of lead with a concentration of 100 $\mu \mathrm{g} / \mathrm{mL}$ was obtained by dissolving appropriate amount of lead nitrate obtained from Beijing Chemical Engineering technique Co. Ltd. in double-distilled water. Working standard solution was obtained by appropriate dilution of the stock standard solution. The concentration for working solutions of AR (Shanghai reagent Third plant) was $1.0 \times 10^{-5} \mathrm{~mol} / \mathrm{L}$. The concentration for working solutions of cetylpyridinium bromide (Sigma-Aldrich) was $1.00 \times 10^{-5} \mathrm{~mol} / \mathrm{L} . \mathrm{NH}_{3} \cdot \mathrm{H}_{2} \mathrm{O}$ solution with different $\mathrm{pH}$ was prepared according to suitable proportion and adjusted $\mathrm{pH}$ values with a $\mathrm{pH}$ meter. All reagents were analytical grade without further purification and doubly distilled water was used throughout.

Into a $10 \mathrm{~mL}$ volumetric tube were added $1 \mathrm{~mL} \mathrm{pH} 7.6$ $\mathrm{NH}_{3} \cdot \mathrm{H}_{2} \mathrm{O}$ buffer solution, $2 \mathrm{~mL}$ of Alizarin red solution, 1.50 $\mathrm{mL}$ cetylpyridinium bromide solution and suitable amount of $\mathrm{Pb}(\mathrm{II})$. The mixture was then diluted to the mark with water and mixed thoroughly. After waiting for $10 \mathrm{~min}$, the RRS spectra of the system was recorded with synchronous scanning at $\lambda_{\mathrm{ex}}=\lambda_{\mathrm{em}}$ by fluorospectrophoto-meter and IRRS of binding product and $\mathrm{I}_{0}$ of reagent blank at selective scattering wavelength were measured. At the same time, the SOS and FDS spectra were recorded by scanning at $\lambda_{\mathrm{ex}}=1 / 2 \lambda_{\mathrm{em}}$ and $\lambda_{\mathrm{ex}}=$ $2 \lambda_{\text {em }}$, respectively. The scattering intensity $I_{S O S}$ and $I_{F D S}$ for the reaction product and $\mathrm{I}_{0 \mathrm{SOS}}$ and $\mathrm{I}_{0 \mathrm{FDS}}$ for the reagent blank at their maximum wavelengths were measured; $\Delta \mathrm{I}_{\mathrm{SOS}}=\mathrm{I}_{\mathrm{SOS}}-\mathrm{I}_{0 \mathrm{SOS}}$, $\lambda I_{\mathrm{FDS}}=\mathrm{I}_{\mathrm{FDS}}-\mathrm{I}_{0 \mathrm{FDS}}$. The absorption spectra were recorded simultaneously.

RESULTS AND DISCUSSION

The resonance Rayleigh scattering (RRS) spectra of $\mathrm{Pb}(\mathrm{II})-\mathrm{AR}-\mathrm{CPB}$ system are shown in Fig. 1. It could be seen

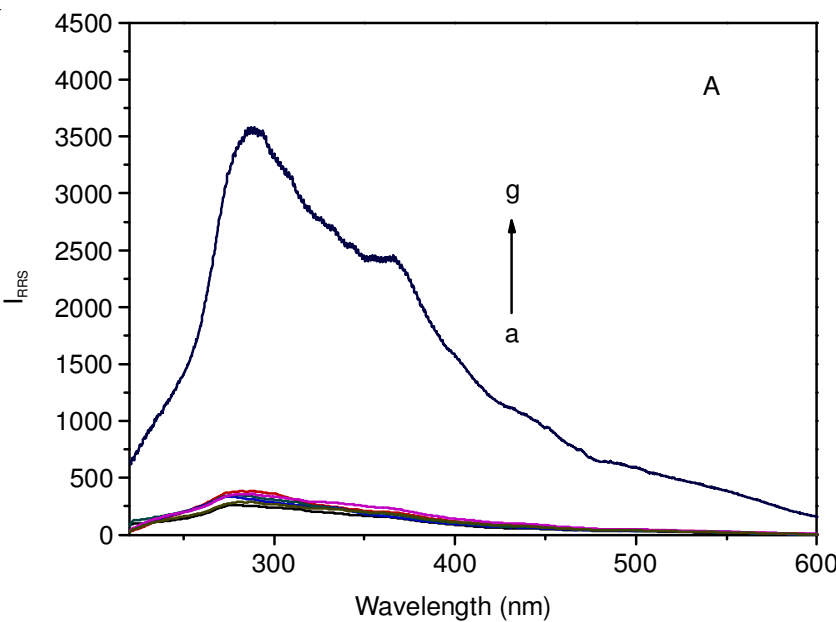

from Fig. 1(A) that: under the experimental conditions, the RRS intensities of $\mathrm{AR}, \mathrm{CPB}, \mathrm{Pb}(\mathrm{II})$ and the binary ligand complexes were very weak. However, when AR-CPB binary chelate reacted with $\mathrm{Pb}$ (II) to form ternary ion-association complex, their RRS intensities increased remarkably and the maximum RRS wavelength was located at $288 \mathrm{~nm}$. Fig. 1B shows that the enhancement of RRS for the system is directly proportional to the concentration of $\mathrm{Pb}$ (II) in certain range. Therefore, the RRS method could be applied to the quantitative determination of $\mathrm{Pb}$ (II).

Second-order scattering (SOS) and frequency doubling scattering (FDS) spectra: The SOS and FDS spectra were recorded by scanning at $\lambda_{\mathrm{ex}}=1 / 2 \lambda_{\mathrm{em}}$ and $\lambda_{\mathrm{ex}}=2 \lambda_{\mathrm{em}}$. Experimental results showed that the SOS and FDS intensities of $\mathrm{AR}, \mathrm{CPB}, \mathrm{Pb}(\mathrm{II})$, AR-CPB, $\mathrm{Pb}$ (II)-CPB, $\mathrm{Pb}$ (II)-AR were very weak. When the AR-CPB binary chelate reacted with $\mathrm{Pb}$ (II) to form ternary ion-association complexes, SOS and FDS intensities were enhanced greatly. The characteristics of the two spectra were similar. As shown in Fig. 2, the maximum SOS and FDS wavelengths appeared at $272 \mathrm{~nm} / 544 \mathrm{~nm}$ for SOS and $780 \mathrm{~nm} / 390 \mathrm{~nm}$ for FDS. As shown in Fig. 3, the enhancement of SOS and FDS intensities of the $\mathrm{Pb}(\mathrm{II})$-ARCPB system were directly proportional to the concentration of $\mathrm{Pb}$ (II). Therefore SOS and FDS methods could be applied to determine $\mathrm{Pb}$ (II).

Effect of acidity: Fig. 4 showed the effect of $\mathrm{pH}$ on RRS intensity. Six solutions including $\mathrm{HOAc}-\mathrm{NaOAc}, \mathrm{HCl}, \mathrm{H}_{2} \mathrm{SO}_{4}$, $\mathrm{NH}_{3} \cdot \mathrm{H}_{2} \mathrm{O}, \mathrm{NaOH}$ and Britton-Robinson, were used to adjust the $\mathrm{pH}$ of the solutions. The results showed that the sensitivity and stability of the $\mathrm{NH}_{3} \cdot \mathrm{H}_{2} \mathrm{O}$ solution were the best. Therefore, the $\mathrm{NH}_{3} \cdot \mathrm{H}_{2} \mathrm{O}$ solution was selected to control the $\mathrm{pH}$ of the solutions. It could be seen from Fig. 4 that the optimum $\mathrm{pH}$ was 7.6. The higher or lower $\mathrm{pH}$ value caused a marked decrease in the $\Delta \mathrm{I}$. And the appropriate amount for the determination of $\mathrm{Pb}(\mathrm{II})$ was $1 \mathrm{~mL}$. So, $1 \mathrm{~mL}$ of $\mathrm{pH} 7.6 \mathrm{NH}_{3} \cdot \mathrm{H}_{2} \mathrm{O}$ solution was chosen as the reaction medium.

Effect of Alizarin red concentration: The effect of the concentration of Alizarin red on RRS intensities was tested and the optimal concentration is in the range of (1.6-2.4) $\times 10^{-5}$ $\mathrm{mol} / \mathrm{L}$. When the concentration of Alizarin red is low, due to

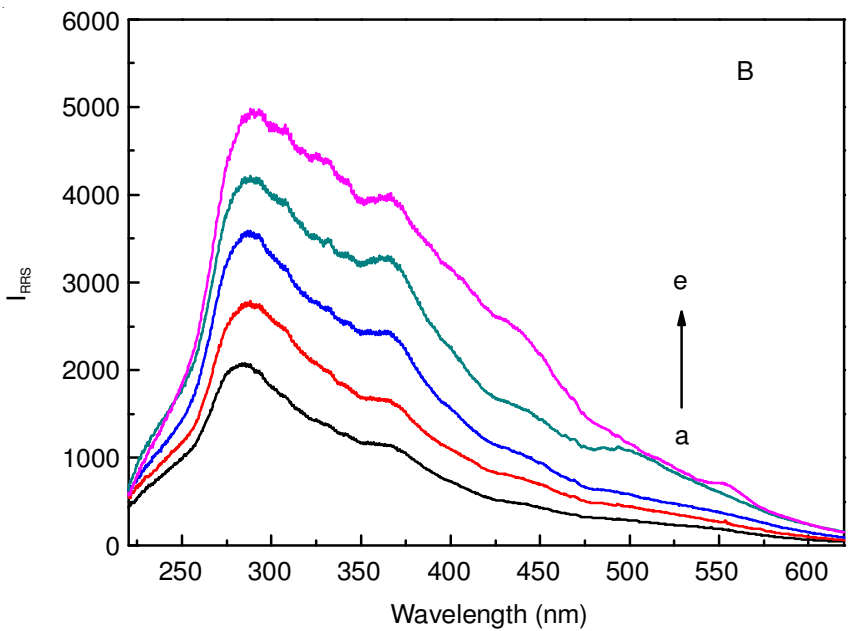

Fig. 1. RRS spectra: (A) The RRS spectra of binding products of $\mathrm{Pb}(\mathrm{II})$ with $\mathrm{AR}$ and CPB. a.AR; b.CPB; c.Pb(II); d. CPB-Pb(II); e. AR-Pb(II); f. AR-CPB; g. AR-CPB-Pb(II). $\mathrm{C}_{\mathrm{AR}}=2.0 \times 10^{-5} \mathrm{~mol} / \mathrm{L} ; \mathrm{C}_{\mathrm{CPB}}=1.0 \times 10^{-5} \mathrm{~mol} / \mathrm{L} ; \mathrm{C}_{\mathrm{Pb}(\mathrm{II})}=1.5 \mu \mathrm{g} / \mathrm{mL}$. (B) The RRS spectra of binding products of Pb(II) with $\mathrm{AR}$ and $\mathrm{CPB}$ for various concentration. $\mathrm{C}_{\mathrm{AR}}=2.0 \times 10^{-5} \mathrm{~mol} / \mathrm{L} ; \mathrm{C}_{\mathrm{CPB}}=1.0 \times 10^{-5} \mathrm{~mol} / \mathrm{L} ; \mathrm{C}_{\mathrm{Pb}(\mathrm{II})}(\mathrm{a}-\mathrm{e}): 0.5,1.0,1.5,2.5,3.0 \mu \mathrm{g} / \mathrm{mL}$ 

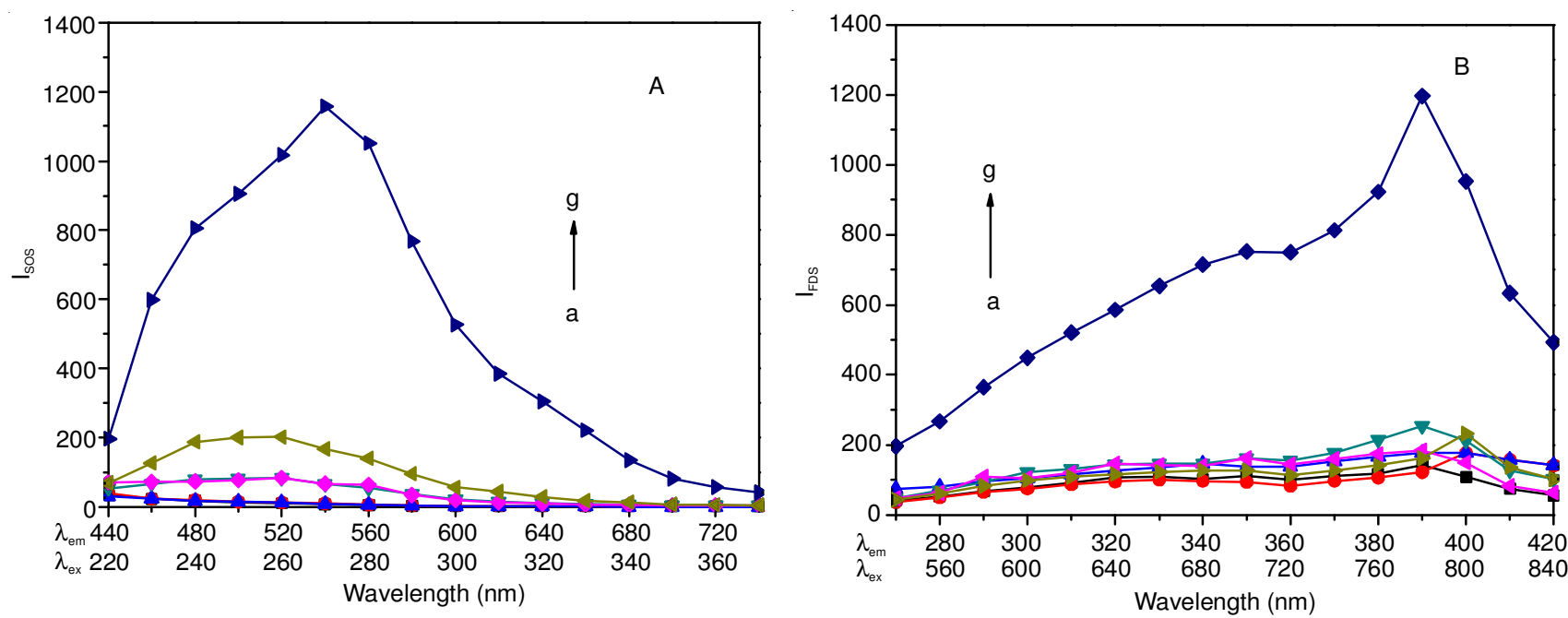

Fig. 2. SOS and FDS spectra. (A) SOS spectra $C_{A R}=2.0 \times 10^{-5} \mathrm{~mol} / \mathrm{L} ; \mathrm{C}_{\mathrm{CPB}}=1.0 \times 10^{-5} \mathrm{~mol} / \mathrm{L} ; \mathrm{C}_{\mathrm{Pb}(\mathrm{II})}=0.5 \mu \mathrm{g} / \mathrm{mL}$. (B) FDS spectra. a. $\mathrm{AR} ; \mathrm{b}$. $\mathrm{CPB} ; \mathrm{c}$. Pb(II); d. AR-CPB; e. Pb(II)-AR ; f. Pb(II)-CPB; g. Pb(II)-AR-CPB. $\mathrm{C}_{\mathrm{AR}}=2.0 \times 10^{-5} \mathrm{~mol} / \mathrm{L} ; \mathrm{C}_{\mathrm{CPB}}=1.0 \times 10^{-5} \mathrm{~mol} / \mathrm{L} ; \mathrm{C}_{\mathrm{Pb}(\mathrm{II})}=2.0 \mu \mathrm{g} / \mathrm{mL}$
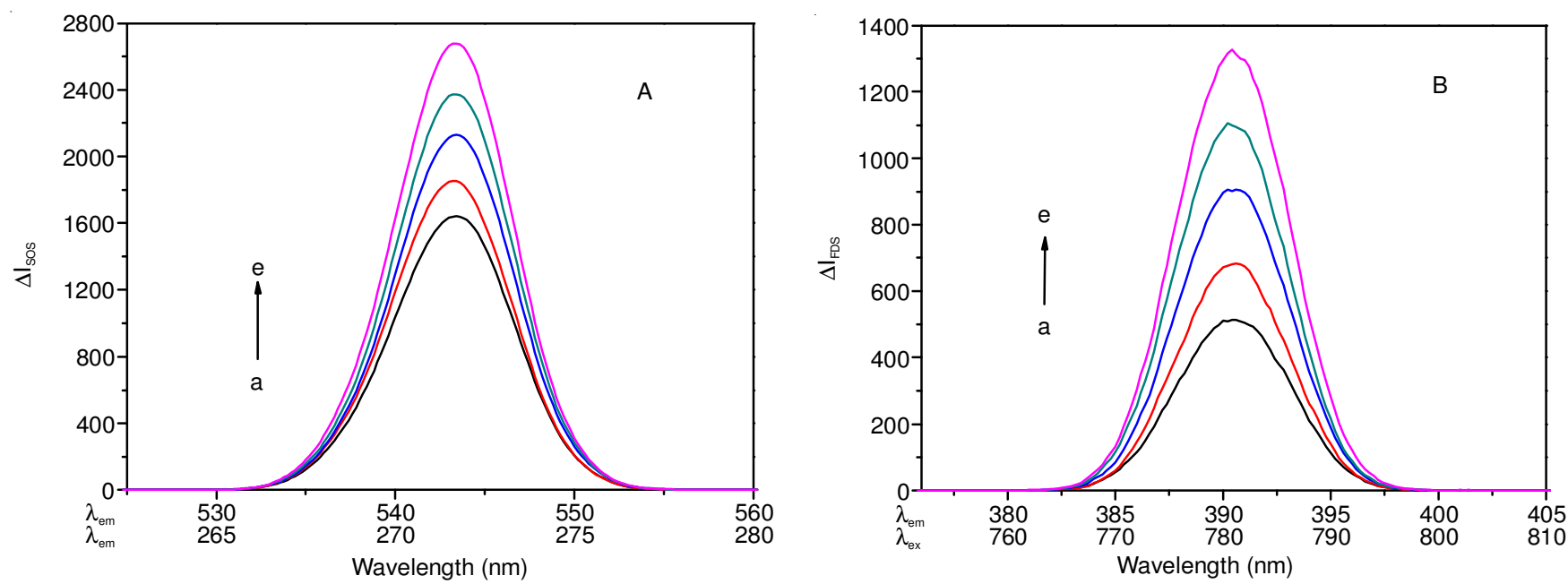

Fig. 3. SOS and FDS spectra. (A) The SOS spectra of binding products of $\mathrm{Pb}$ (II) with $\mathrm{AR}$ and $\mathrm{CPB}$ for various concentration. $\mathrm{C}_{\mathrm{Pb} \text { (II) }}$ (a-e): $0.5,1.0,1.5,2.0$, $2.5 \mu \mathrm{g} / \mathrm{mL} ; \mathrm{C}_{\mathrm{AR}}=2.0 \times 10^{-5} \mathrm{~mol} / \mathrm{L} ; \mathrm{C}_{\mathrm{CPB}}=1.0 \times 10^{-5} \mathrm{~mol} / \mathrm{L}$. (B) The SOS spectra of binding products of $\mathrm{Pb}(\mathrm{II})$ with $\mathrm{AR}$ and $\mathrm{CPB}$ for various concentration. $\mathrm{C}_{\mathrm{AR}}=2.0 \times 10^{-5} \mathrm{~mol} / \mathrm{L} ; \mathrm{C}_{\mathrm{CPB}}=1.0 \times 10^{-5} \mathrm{~mol} / \mathrm{L} ; \mathrm{C}_{\mathrm{Pb}(\mathrm{II})}(\mathrm{a}-\mathrm{e}): 0.5,1.0,1.5,2.0,2.5 \mu \mathrm{g} / \mathrm{mL}$

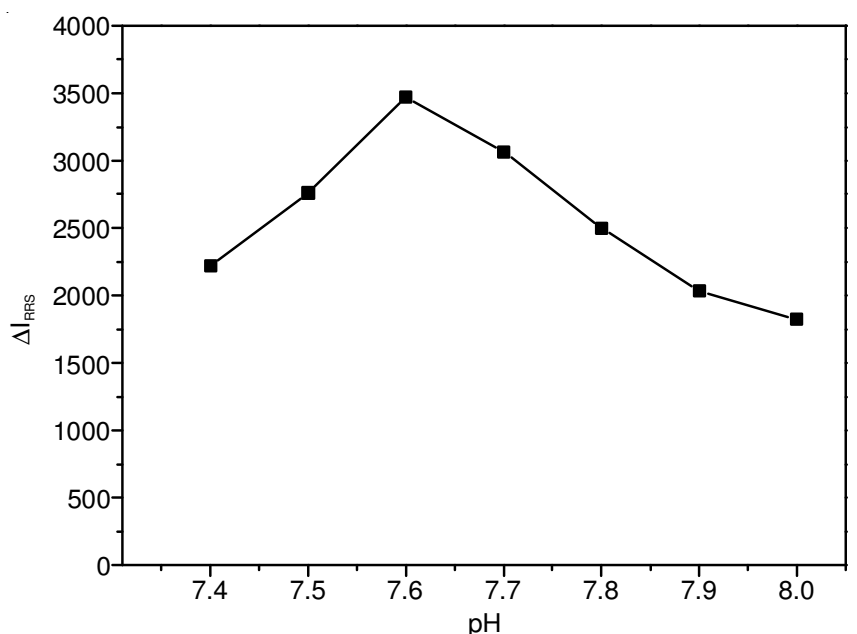

Fig. 4. Effect of acidity. $(\mathrm{pH}=7.4 ; 7.5 ; 7.6 ; 7.7 ; 7.8 ; 7.9 ; 8.0)$ Experimental conditions: $\mathrm{C}_{\mathrm{AR}}=2.0 \times 10^{-5} \mathrm{~mol} / \mathrm{L} ; \mathrm{C}_{\mathrm{CPB}}=1.0 \times 10^{-5} \mathrm{~mol} / \mathrm{L} ; \mathrm{C}_{\mathrm{Pb}(\mathrm{II})}=$ $2.0 \mu \mathrm{g} / \mathrm{mL}$

its incomplete reaction with $\mathrm{Pb}(\mathrm{II})$ and $\mathrm{CPB}$, the relative scattering intensity $(\Delta \mathrm{I})$ was low. With an increase of Alizarin red concentration, $\Delta \mathrm{I}$ enhanced gradually. However, when the concentration of Alizarin red was higher than the optimum concentration, the RRS intensity of blank reagent increased, the relative RRS intensities of the system will decrease. Thus, $2 \times 10^{-5} \mathrm{~mol} / \mathrm{L}$ Alizarin red solution was chosen as a suitable Alizarin red concentration.

Effect of CPB concentration: The effect of the concentration of CPB on RRS intensities of CPB system was investigated. The results indicated that the RRS intensity enhanced gradually with the increasing of $\mathrm{CPB}$ concentration and the optimum concentration of CPB was $1.5 \times 10^{-5} \mathrm{~mol} / \mathrm{L}$. When the concentration of CPB was lower than the above concentration, the reaction of $\mathrm{CPB}$ with $\mathrm{Pb}(\mathrm{II})-\mathrm{AR}$ binary complex was not complete and the RRS intensity of the solution was weaker. When the concentration of CPB was higher, the RRS intensity of blank reagent increased, resulting in a decrease in $\Delta \mathrm{I}$. Therefore, in the experiment, we chose $1.5 \times 10^{-5} \mathrm{~mol} / \mathrm{L}$ as the optimum addition of CPB.

Effect of addition order of reagents: The effect of different order of addition of reagents on the scattering intensity of RRS for the system was investigated. The experimental 
results showed that the optimum addition order of reagents was $\mathrm{AR}, \mathrm{CPB}, \mathrm{Pb}(\mathrm{II})$ and $\mathrm{NH}_{3} \cdot \mathrm{H}_{2} \mathrm{O}$.

Effect of ionic strength: The effect of ionic strength on the intensities of RRS for the system was studied with $\mathrm{NaCl}$. The result showed that it had little effect on the RRS when $\mathrm{NaCl}$ concentration was lower than $1.4 \times 10^{-2} \mathrm{~mol} / \mathrm{L}$, but it would gradually decrease with the increasing of the concentration of $\mathrm{NaCl}$. Due to the main force of the system which is electrostatic attraction and the existence of the large number of $\mathrm{Na}^{+}$and $\mathrm{Cl}^{-}$will compete with the association complex. So, the ionassociation reaction should be under a low ionic strength condition.

Reaction speed and stability of ion-association complex: Under the room temperature, the formation of ion-association was in need of about 10 min then the $\Delta \mathrm{I}_{\mathrm{RRS}}$ would be kept constant in $24 \mathrm{~h}$.

Sensitivity of the method: Under the optimum experimental conditions, the different concentrations of $\mathrm{Pb}(\mathrm{II})$ reacted with Alizarin red and $\mathrm{CPB}$ to form ternary complexes and the relative scattering intensities $\Delta \mathrm{I}_{\mathrm{RRS}}, \Delta \mathrm{I}_{\mathrm{SOS}}$ and $\Delta \mathrm{I}_{\mathrm{FDS}}$ of the ternary complexes were measured at their maximum scattering wavelengths after $10 \mathrm{~min}$, separately. The calibration graphs of $\Delta \mathrm{I}_{\mathrm{RRS}}, \Delta \mathrm{I}_{\mathrm{SOS}}$ and $\Delta \mathrm{I}_{\mathrm{FDS}}$ against the concentrations of $\mathrm{Pb}(\mathrm{II})$ were constructed. The linear range, linear regression equation, correlation coefficients and detection limit $(3 \sigma)$ were shown in Table-1. It was evident that they all had highly sensitivities and the detection limits of the methods were $2.1 \mathrm{ng} / \mathrm{mL}$ for RRS method, $7.4 \mathrm{ng} / \mathrm{mL}$ for SOS and $8.6 \mathrm{ng} / \mathrm{mL}$ for FDS, respectively. The sensitivity of RRS method was higher than those of SOS and FDS methods, so the RRS method was taken for the following studies including effects of interfering substance and analytical application.

Effects of coexisting substances: Under the optimum conditions, the effects of some coexisting substances on the determination of $\mathrm{Pb}$ (II) by RRS method were investigated and the results were given in Table-2. As shown, when the relative error was lower than $\pm 5 \%$ and $\mathrm{Pb}$ (II) was about $1.0 \mu \mathrm{g} / \mathrm{mL}$, some substances, such as $\mathrm{NH}_{4}^{+}, \mathrm{Mg}^{2+}, \mathrm{Mn}^{2+}, \mathrm{SO}_{4}^{2-}, \mathrm{H}_{2} \mathrm{PO}_{4}^{-}$, $\mathrm{Cu}^{2+}, \mathrm{Cl}^{-}$do not interfere with the determination. Therefore, the RRS method has a good selectivity and can be used in real samples.

Interaction mechanism: Under the optimum conditions, the formation mechanism of AR-CPB-Pb(II) ternary ionassociation complex was investigated. On the one hand, AR is a kind of organic dye, which contains both sulfonic acid group and hydroxy. In $\mathrm{NH}_{3} \cdot \mathrm{H}_{2} \mathrm{O}$ solution ( $\mathrm{pH}$ 7.6), the dissociation of sulfonic acid group made the AR exist in anionic form, it is conducive to form strong coordination bond with $\mathrm{Pb}$ (II). On the other hand, CPB is a kind of surfactant, due to the hydrophobic force of its long carbon chain, CPB could combined with AR-Pb(II) binary complex to form a larger particle size of the AR-CPB-Pb(II) ternary ion-association complex in the solution. Furthermore, $\mathrm{CPB}$ also has a certain sensitization effect, which is conducive to form AR-CPB-Pb(II) ternary ionassociation complex.

Reasons of resonance Rayleigh scattering (RRS) enhancement: There are several reasons that the formation of the ternary ion-association lead to the enhancement of RRS. (1) As is known to all, resonance Rayleigh scattering is an absorption-rescattering process produced by the resonance between Rayleigh scattering and light absorption with equal frequency. Therefore, RRS spectrum should be closely related to the absorption spectrum. By research, we found that the RRS peak is located at its absorption band and it have good corresponding relationship with the absorption peaks, which results in a resonance enhanced effect and leads to RRS intensity enhanced remarkably. (2) In pH 7.6 $\mathrm{NH}_{4} \mathrm{OH}$ solution, $\mathrm{AR}$ is easy to dissolve in water. It can react with $\mathrm{Pb}$ (II) to form the ion-association complexes. Besides, these association complexes can further assemble to form hydrophobic particles. Thus, they will form the hydrophobic interface with the aqueous phase and the formation of this hydrophobic interface will be advantageous to scattering enhancement ${ }^{16}$. (3) According to the formula of Rayleigh scattering: $\mathrm{I}=\mathrm{KcMI}_{0}{ }^{17}$, that

\begin{tabular}{ccccc}
\multicolumn{5}{c}{ TABLE-1 } \\
RELATED PARAMETERS OF CALIBRATION CURVES \\
\hline \multirow{2}{*}{ Method } & $\begin{array}{c}\text { Linear range } \\
(\mathrm{c}, \mu \mathrm{g} / \mathrm{mL})\end{array}$ & $\begin{array}{c}\text { Linear regression } \\
\text { equation }(\mathrm{c}, \mu \mathrm{g} / \mathrm{mL})\end{array}$ & $\begin{array}{c}\text { Correlation coefficient }(\mathrm{r}) \\
(\mathrm{n}=5)\end{array}$ & $\begin{array}{c}\text { Detection limit } \\
(3 \sigma, \mathrm{ng} / \mathrm{mL})\end{array}$ \\
\hline RRS & $0.12-3.78$ & $\Delta \mathrm{I}=4816.2 \mathrm{C}+634.40$ & 0.9983 & 2.1 \\
SOS & $0.09-2.86$ & $\Delta \mathrm{I}=1253.2 \mathrm{C}+705.61$ & 0.9964 & 7.4 \\
FDS & $0.07-2.86$ & $\Delta \mathrm{I}=1908.9 \mathrm{C}+209.08$ & 0.9976 & 8.6 \\
\hline
\end{tabular}

TABLE-2

EFFECT OF COEXISTING SUBSTANCES $\left(\mathrm{C}_{\mathrm{Pb}(\mathrm{II})}: 1.0 \mu \mathrm{g} / \mathrm{mL}\right)$

\begin{tabular}{|c|c|c|c|c|c|}
\hline Foreign substances & Concentration $(\mu \mathrm{g} / \mathrm{mL})$ & Change in $\mathrm{I}_{\mathrm{RRS}}(\%)$ & Foreign substances & Concentration $(\mu \mathrm{g} / \mathrm{mL})$ & Change in $\mathrm{I}_{\mathrm{RRS}}(\%)$ \\
\hline $\mathrm{Na}^{+}$ & 300 & -3.30 & $\mathrm{Mg}^{2+}$ & 152 & 2.97 \\
\hline $\mathrm{K}^{+}$ & 300 & 1.38 & $\mathrm{Ba}^{2+}$ & 124 & 4.28 \\
\hline $\mathrm{Cl}^{-}$ & 268 & -3.30 & $\mathrm{Ca}^{2+}$ & 106 & -4.43 \\
\hline $\mathrm{NO}_{3}^{-}$ & 250 & 0.48 & $\mathrm{Al}^{3+}$ & 67 & 3.98 \\
\hline $\mathrm{Br}^{-}$ & 240 & -4.89 & $\mathrm{Ni}^{2+}$ & 55 & -0.49 \\
\hline $\mathrm{I}^{-}$ & 226 & 4.39 & $\mathrm{Cu}^{2+}$ & 48 & -3.56 \\
\hline $\mathrm{NO}_{2}^{-}$ & 212 & -1.16 & $\mathrm{Fe}^{3+}$ & 15 & 4.02 \\
\hline $\mathrm{NH}_{4}^{+}$ & 166 & -1.71 & $\mathrm{Cr}^{3+}$ & 11 & 5.01 \\
\hline $\mathrm{SO}_{4}^{2-}$ & 121 & 4.25 & $\mathrm{C}_{2} \mathrm{O}_{4}^{2-}$ & 91 & 2.49 \\
\hline $\mathrm{S}_{2} \mathrm{O}_{8}{ }^{2-}$ & 110 & -4.36 & $\mathrm{IO}_{3}^{-}$ & 30 & 3.72 \\
\hline $\mathrm{Mn}^{2+}$ & 40 & 4.27 & $\mathrm{SCN}^{-}$ & 10 & -0.12 \\
\hline
\end{tabular}




\begin{tabular}{cccccc}
\hline \multicolumn{7}{c}{ TABLE-3 } \\
& \multicolumn{7}{c}{ DETERMINATION OF Pb(II) IONS CONCENTRATION IN VARIOUS WATER SAMPLES } \\
\hline Samples & Found $(\mu \mathrm{g} / \mathrm{mL})$ & Added $(\mu \mathrm{g} / \mathrm{mL})$ & Found $(\mathrm{n}=5, \mu \mathrm{g} / \mathrm{mL})$ & Recovery $(\%)$ & RSD $(\%)$ \\
\hline Drinking water & $\mathrm{ND}^{\mathrm{a}}$ & 1.20 & $1.17,1.19,1.22,1.23,1.24$ & 100.8 & 2.41 \\
Pond water & $\mathrm{ND}$ & 1.20 & $1.15,1.15,1.22,1.24,1.26$ & 100.3 & 4.26 \\
Tap water & $\mathrm{ND}$ & 1.20 & $1.15,1.15,1.19,1.23,1.25$ & 99.5 & 3.82 \\
River water & $\mathrm{ND}$ & 1.20 & $1.17,1.18,1.23,1.24,1.27$ & 101.5 & 3.45 \\
\hline${ }^{\text {a }}$ Not detected. & & & & & \\
\hline
\end{tabular}

is, when the incident light intensity $\left(\mathrm{I}_{0}\right)$ and the concentration of the solution are constant, the scattering intensity (I) is proportional to the molecular weight $(\mathrm{M})$ of the particle. The composition of $\mathrm{Pb}$ (II)-AR-CPB ternary ion-association complex was established by using move balance method and the molar ratio method and the ratio of $\mathrm{CPB}, \mathrm{Pb}(\mathrm{II})$ and $\mathrm{AR}$ is $2: 1: 2$. The increase of the molecular weight is conducive to the enhancement of scattering intensity.

Application in water samples: The new method in this present work was then evaluated the determination of trace amounts of $\mathrm{Pb}(\mathrm{II})$ ions in drinking water, pond water, tap water and river water. The analytical results obtained are summarized in Table-3. The recovery efficiencies of $\mathrm{Pb}$ (II) ion were obtained in the range of 99.5-101.5\%, which are acceptable under all conditions.

\section{Conclusion}

The present paper described a highly convenient, rapid and accurate method for the determination of trace amounts of lead. Our results demonstrated that at $\mathrm{pH} 7.6$ basic medium, lead interacted with Alizarin red and cetylpyridinium bromide to form a ternary ion-association complex. As a result, the new spectra of resonance Rayleigh scattering, second-order scattering and frequence doubling scattering appeared and their intensities were enhanced greatly. In a certain range, the three kinds of scattering intensities were proportional to the determination of lead and then the novel method for determining lead was established. The method was successfully applied to the determination of lead in water samples with standard addition method. It was proposed that the technique can be developed that the technique can be developed further to monitor lead.

\section{ACKNOWLEDGEMENTS}

This work was supported by the Foundation of National Natural Science foundation of China (Grant No. 41101223), Foundation of Chongqing Education Commission of China (No. KJ111206, KJ111203) and Chongqing university of arts and science (No. 2011HH16).

\section{REFERENCES}

1. EPA, http://www.epa.gov/lead/pubs/leadinfo.htm\#health.

2. T. Asano, K. Yabusaki, P.-C. Wang and A. Iwasaki, Spectrochim. Acta A, 75, 819 (2010,).

3. K.C. Armstrong, C.E. Tatum, R.N. Dansby-Sparks, J.Q. Chambers and Z.-L. Xue, Talanta, 82, 675 (2012).

4. B. Ninwong, S. Chuanuwatanakul, O. Chailapakul, W. Dungchai and S. Motomizu, Talanta, 96, 75 (2012).

5. A. Baysal, N. Ozbek and S. Akman, Food Chem., 123, 901 (2010).

6. A. Baysal and S. Akman, Spectrochim. Acta B, 65, 340 (2010).

7. M. Chamsaz, J. Akhoundzadeh and M.H. Arbab-Zavar, J. Adv. Res., 4, 361 (2013).

8. H. Wu, H. Wen, B. Han, B. Du, J. Lu and J. Tian, Microchim Acta, 166, 41 (2009).

9. Q. Zhou, N. Zhao and G. Xie, J. Hazard. Mater, 189, 48 (2011).

10. Y. Song, S. Liu, Z. Liu and X. Hu, Spectrochim. Acta A, 78148 (2011).

11. A. Yi, Z. Liu, S. Liu and X. Hu, Luminescence, 24, 23 (2009).

12. D. Gao, N. He, Y. Tian, Y. Chen, H. Zhang and A. Yu, Spectrochim. Acta A, 68, 573 (2007).

13. X. Long, S. Bi, X. Tao, Y. Wang and H. Zhao, Spectrochim. Acta A, 60, 455 (2004).

14. P. Zhang, S. Chen, Y. Kang and Y. Long, Spectrochim. Acta A, 99, 347 (2012).

15. Z. Chen, G. Liu, M. Chen, Y. Peng and M. Wu, Anal. Biochem., 384, 337 (2009).

16. S.P. Liu and X.L. Hu. Chin. Sci. Bull., 36, 317 (2006).

17. Cyclopaedia in China, Biology II, Cyclopaedia in China Press, Beijing, p. 1374 (1991). 